\title{
Diagnosis and management of insulinoma: current best practice and ongoing developments
}

This article was published in the following Dove Press journal:

Research and Reports in Endocrine Disorders

25 August 2015

Number of times this article has been viewed

\author{
Aida Taye \\ Steven K Libutti \\ Department of Surgery, Montefiore \\ Medical Center/Albert Einstein, \\ College of Medicine, Bronx, NY, USA
}

Correspondence: Steven K Libutti Department of Surgery, Montefiore Medical Center, Medical Arts Pavilion, 3400 Bainbridge Avenue, Bronx, NY 10467, USA

$\mathrm{Tel}+|7| 8920423 \mid$

Fax + I 7188821279

Email slibutti@montefiore.org

\begin{abstract}
Insulinoma is a predominantly benign and rare neuroendocrine tumor. Patients with insulinoma typically present with neurologic symptoms from hypoglycemia, such as confusion, dizziness, and behavioral changes, as well as symptoms from a surge in catecholamine levels, such as palpitations, diaphoresis, and tachycardia. Symptomatic patients usually have glucose levels below $55 \mathrm{mg} / \mathrm{dL}$ and are relieved of their symptoms when carbohydrate is administered. The 48-hour test, performed by measuring blood glucose levels of insulin, $\mathrm{C}$ peptide, and proinsulin collected every 4-6 hours in fasting patients, accurately confirms the diagnosis of insulinoma in the majority of the patients. Once the diagnosis is confirmed, the next step in management involves identifying the location of the tumor and successfully removing it surgically. In the last two decades, clinicians have moved away from invasive angiography for preoperative localization. A multiphase computed tomography (CT) can be used to localize the lesion and evaluate for metastasis. If CT does not detect the lesion, selective arterial calcium stimulation test is recommended to identify the region of the lesion in the pancreas. Some argue that all preoperative localization techniques are superfluous. The combination of intraoperative ultrasound and operative palpation has led to a nearly $100 \%$ success rate. Recently, in select cases, laparoscopic enucleations and resections of insulinomas have been performed with shorter length of stay and faster recovery time. Despite advances in imaging, a little over $10 \%$ of insulinoma patients undergo reexploration for missing lesions. Patients who are not candidates for tumor resections or awaiting surgery have had symptomatic relief from diazoxide and somatostatin analogs among various medical therapies. In patients with metastatic insulinoma, progressionfree survival and overall survival are reported from newly approved chemotherapeutic agents. Liver-directed therapies, such as ablation and selective radiation, and cytoreductive surgery have also been performed for symptom control and prolonging survival.
\end{abstract}

Keywords: malignant insulinoma, pancreas, localization, surgery

\section{Introduction}

Insulinomas are rare functional neuroendocrine tumors (NETs) of the pancreas. The challenges of insulinoma diagnosis, localization, and surgical management have seen changes over the last few decades. In addition to describing the past standards of care for insulinoma, this review will elaborate on present-day best practice and recent advances made in the diagnosis and management

Our current understanding of insulinomas began with the discovery of pancreatic islet cells by Paul Langerhans in $1869 .{ }^{1-3}$ In 1922, the extraction of insulin, or “isletin", from a dog's pancreas by Banting and Best led the way to several studies that examined the physiologic significance of the hormone. ${ }^{2}$ The following year, in 1923, Harris introduced the clinical possibility of spontaneous "hyperinsulinism", in 
patients with blood sugars below $70 \mathrm{mg}$ per $100 \mathrm{cc}$ whose symptoms improved by feeding. ${ }^{2}$ In 1927, Wilder and colleagues established an association between hyperinsulinism and a functional islet cell tumor. They performed surgical exploration on a patient with hyperinsulinism only to discover an unresectable islet cell carcinoma with hepatic metastasis. ${ }^{2}$ Two years later, Roscoe Graham was able to resect an islet cell tumor documenting the first surgical cure of hyperinsulinemia. ${ }^{2}$ In 1935, Whipple and Frantz published a manuscript summarizing the historic advances that defined insulinomas, along with their own observations. This paper, represented the first published account of the diagnostic "Whipple's Triad": (1) symptoms of hypoglycemia provoked by fasting; (2) circulating glucose level less than $50 \mathrm{mg} / \mathrm{dL}$ at the time symptoms presented; and (3) the relief of symptoms with the administration of glucose. $^{2}$

\section{Demographics}

The incidence of insulinoma is four per million persons each year, and insulinomas often present as a solitary pancreatic tumor. $^{1}$ The majority of insulinomas are small, measuring less than $2 \mathrm{~cm}^{4,5}$ Despite its rare occurrence, insulinoma is the most common functional neuroendocrine tumor. ${ }^{6}$ Although the large majority of insulinomas are sporadic, up to $10 \%$ may be associated with hereditary multiple endocrine neoplasia type I (MEN-1). ${ }^{7} \mathrm{MEN}-1$ is an autosomal-dominant syndrome affecting mainly the parathyroid glands, anterior pituitary, endocrine pancreas, and duodenum, due to inactivation of the MEN1 gene on chromosome 11q13.

Insulinoma in patients with MEN-1 have additional challenges not encountered in sporadic cases. ${ }^{8} \mathrm{MEN}-1$-associated insulinomas tend to occur throughout the pancreas, are almost always multifocal, and develop earlier than sporadic pancreatic endocrine tumors. ${ }^{7}$ Genetic testing for MEN1 gene should be offered to patients with insulinoma in whom the diagnosis of MEN-1 is considered. Recurrence of insulinoma is also greater among patients with MEN-1 syndrome, $21 \%$ at 10 years compared with $5 \%$ at 10 years for those without the syndrome. ${ }^{1,8,9} \mathrm{MEN}-1$ syndrome-associated insulinomas at times continue to be present despite simple enucleation and local resections. Surgical management of insulinomas associated with MEN-1 should be guided by two principles: total removal of gross disease and safe prophylactic pancreatic resection. ${ }^{8}$ It is therefore essential to address these multifocal lesions by performing distal pancreatectomy to the portal vein, along with enucleations of tumors in the head of the pancreas using intraoperative ultrasound (IOUS) $)^{6,8}$ Such a procedure provides prophylactic resection to minimize recurrence and also prevents endocrine and exocrine pancreatic insufficiency. ${ }^{3}$

\section{Clinical presentation and diagnosis}

Diagnosing insulinoma precisely requires keen clinical observation and laboratory tests. Diverse symptoms are described in patients presenting with this tumor. Unfortunately only $53 \%$ of patients are diagnosed within 5 years of experiencing their first symptom. ${ }^{10}$ Spontaneous hypoglycemia from insulinoma can cause neuroglycopenic symptoms. Insulinomas typically present with neurologic symptoms of confusion, dizziness, and behavioral changes. ${ }^{10-12}$ In severe cases, patients can present with seizures and coma. ${ }^{10-12}$ Glucose levels below $55 \mathrm{mg} / \mathrm{dL}$ produces a surge in catecholamine levels that subsequently cause palpitations, trembling, diaphoresis, and tachycardia. ${ }^{3,11}$ All these symptoms are relieved or prevented when the patient consumes glucose rich food, as described by Whipple and Frantz (Table 1$){ }^{2}$

It is important to understand the mechanism of insulin secretion in order to understand the significance of biochemical assays used to detect insulinomas. Proinsulin secreted from $\beta$-cells of the pancreatic islets of Langerhans is cleaved into insulin and C-peptide. ${ }^{1,3,13}$ Both proinsulin and C-peptide levels in the blood are inappropriately elevated during events of hypoglycemia in a patient with insulinoma. As a result, serum insulin level is also excessively high despite low blood glucose level in these patients. ${ }^{1,3,13}$ Prescribed insulin does not have C-peptide, and hence, hypoglycemia caused by exogenous insulin administration will show suppressed C peptide levels. ${ }^{1,3,13}$

Once a high clinical suspicion for insulinoma is confirmed, biochemical tests based on prolonged supervised fasting are conducted to confirm the diagnosis. The 72-hour monitored fast has been the gold standard for diagnosing this tumor for over 80 years. ${ }^{3,9,14}$ The protocol entails measuring levels of plasma glucose, insulin, $\mathrm{C}$ peptide, and proinsulin in the same specimen and repeating the measurements every 6 hours until the plasma glucose level is $\leq 60 \mathrm{mg} / \mathrm{dL}$. At this point, the interval is reduced to every $1-2$ hours, and

Table I Symptoms of insulinoma and frequency

\begin{tabular}{ll}
\hline Neuroglycopenic symptoms & Adrenergic symptoms \\
\hline Confusion (80\%) & Diaphoresis (69\%) \\
Visual disturbances (59\%) & Tremors (24\%) \\
Amnesia or coma (47\%) & Palpitations (12\%) \\
Abnormal behavior (36\%) & Hyperphagia/weight gain (50\%) \\
Seizures (17\%) &
\end{tabular}

Note: Data are from multiple studies. ${ }^{6,9,11,13}$ 
the fast is terminated either when the plasma glucose level is $\leq 45 \mathrm{mg} / \mathrm{dL}$ or the patient has signs and symptoms of hypoglycemia. ${ }^{1}$ The absence of signs and symptoms typical of hypoglycemia during a 72-hour fast excludes the diagnosis of a hypoglycemic disorder. ${ }^{1}$ In addition to a low plasma glucose level, the interpretation of a positive 72-hour fast is suggested by the following parameters: increased levels of insulin ( $\geq 6 \mu \mathrm{U} / \mathrm{mL})$, C peptide ( $\geq 0.2 \mathrm{nmol} / \mathrm{L})$, and proinsulin $(\geq 5 \mathrm{pmol} / \mathrm{L})$, and an absence of sulfonylurea in the plasma.

Despite long-standing and reliable use of the 72-hour monitored fast, recent work at the National Institutes of Health strongly supports the use of a 48-hour fast and measurements of plasma insulin and proinsulin without prolonged fasting or other stimulation or suppression. Additionally, the protocol for the 72-hour test could be different from center to center, whereas the 48-hour test is easily reproducible and cost effective. ${ }^{9}$ The 48 -hour test is conducted by measuring blood glucose levels of insulin, $\mathrm{C}$ peptide, and proinsulin collected every 4-6 hours. Sulfonylurea is also measured, as it can cause hypoglycemia and is not present in patients with insulinoma. ${ }^{1}$ The test is continued in a similar fashion to the 72-hour fast until the patient develops hypoglycemia, defined as plasma glucose below $40 \mathrm{mg} / \mathrm{dL}$, and neuroglycopenic symptoms as mentioned earlier. ${ }^{9}$ Hypoglycemic patients with inappropriate insulin and $\mathrm{C}$ peptide levels, and negative sulfonylurea screen then go on to have localization studies. ${ }^{9}$ In one study, for $95 \%$ of insulinomas, the fast was terminated at 48 hours and very few were required to fast the full 72 hours, when the subtle signs of neuroglycopenia were not picked up. ${ }^{9}$ It is therefore essential to note that very infrequently, a 72-hour test may be required to evoke evident hypoglycemia.

\section{Preoperative localization}

Once the biochemical diagnosis of insulinoma is confirmed, the next step is preoperative localization. The most effective method of localizing insulinomas is still a matter of controversy as both preoperative and intraoperative approaches have been advocated. Most surgeons value preoperative imaging to evaluate for evidence of metastatic disease. This allows the surgeon to discuss with the patient the extent and type of surgery that is planned. ${ }^{13}$ Preoperative localization of insulinomas can be noninvasive or invasive (Figure 1). ${ }^{15}$ Noninvasive imaging modalities include abdominal ultrasonography, bolus-enhanced helical computed tomography (CT), magnetic resonance imaging (MRI), and somatostatin receptor scintigraphy. Invasive studies are selective angiography, transhepatic portal venous sampling, endoscopic ultrasonography (EUS), and selective arterial calcium stimulation (SACS). ${ }^{15,16}$ While preoperative localization increases intraoperative success, some have argued that preoperative localization is not necessary. ${ }^{16}$ They suggest that the combination of surgical exploration and IOUS can identify more than $90 \%$ of insulinomas. ${ }^{16}$

A recent 2014 systematic review of all localization techniques of insulinoma, including preoperative noninvasive and invasive methods in 6,222 published insulinoma cases, evaluated the success of noninvasive and invasive techniques. ${ }^{15}$ With the use of ultrasonography in $34.4 \%$ of cases, insulinomas were correctly localized in only one-third of the cases. In $95 \%$ of the studies, ultrasonography had an average sensitivity of less than $70 \%$. MRIs had the highest sensitivity in identifying the small pancreatic insulinomas, but the mean sensitivity remained approximately $45 \%$. MRIs were also applied only $9.5 \%$ of the time and lacked good patient compliance. SSTR scintigraphy was performed less than $1 \%$ of the time and localized insulinomas only $24.6 \%$ of the time. CT demonstrated sensitivity ranging from $2 \%$ to $95.3 \%$ in various studies and correctly identified insulinomas in only $44 \%$ of cases. The average sensitivity of CT was less than $70 \%$ in the majority of reports. ${ }^{15}$ However, with the use of dynamic CT with native, arterial, and portal vein phases, insulinomas were better localized, with increased sensitivities of $94 \%, 95.3 \%$, and $83 \%$, respectively. Contrast-enhanced CT was also routinely used in most cases to rule out liver metastases. $^{15}$

A variety of invasive preoperative localization techniques have been used for localization. Selective digital subtraction angiography was considered the gold standard for preoperative localization of insulinoma, with success rate above $90 \% .^{3,15}$ This success has been difficult to match after the 1990 s as only $29 \%-50 \%$ of insulinomas were localized using arteriography. ${ }^{5,15}$ Additional problems with cost, and technical difficulties have also impacted its utility as a first-line study for insulinoma. Moreover, the success, availability, and increased use of the aforementioned noninvasive diagnostic techniques have also contributed to the decreased application of invasive angiography. An invasive localization study that has also fallen out of favor is transhepatic portal venous sampling. Here, a percutaneous and transhepatic catheter is passed into a branch of the portal vein, followed by introduction of the catheter into small veins draining the pancreas. ${ }^{13,15}$ An elevated insulin level sampled from these veins reveals the location of the insulinoma in the pancreas. Although transhepatic portal venous sampling has a sensitivity 


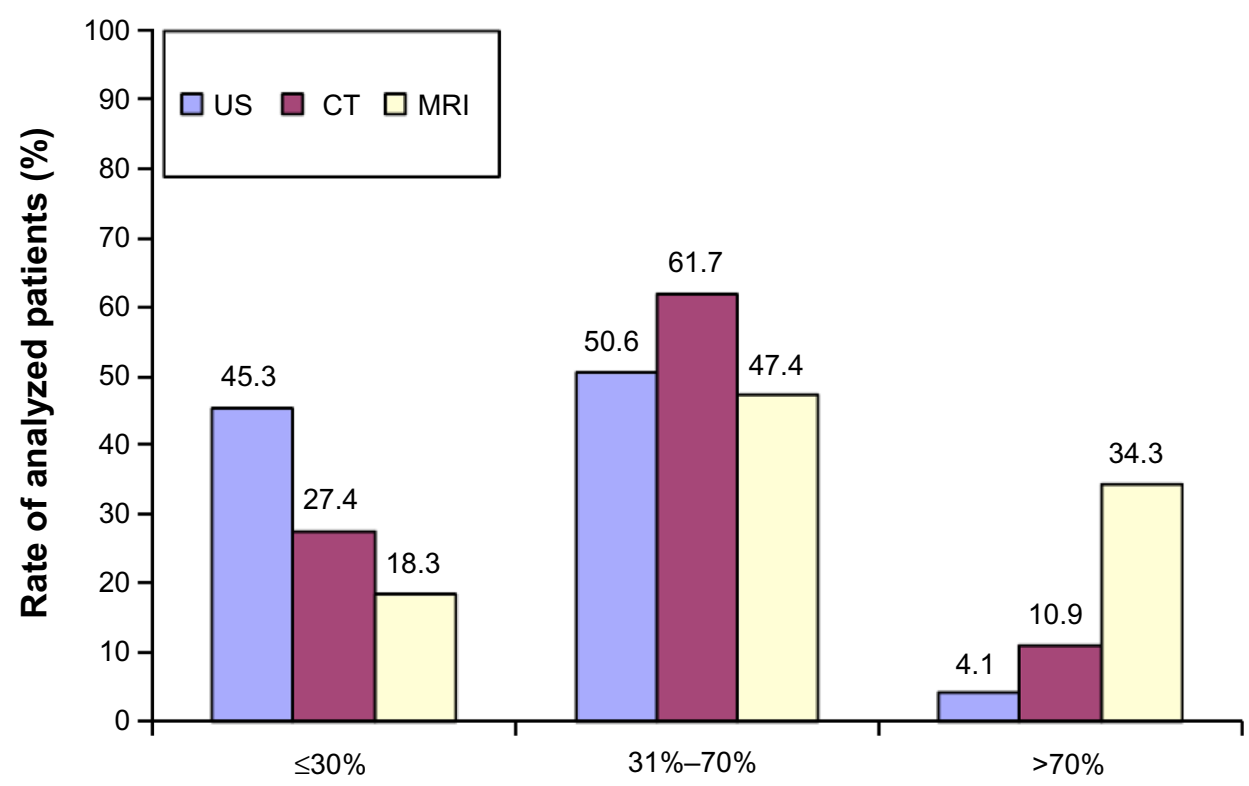

Distribution of sensitivity of preoperative noninvasive methods

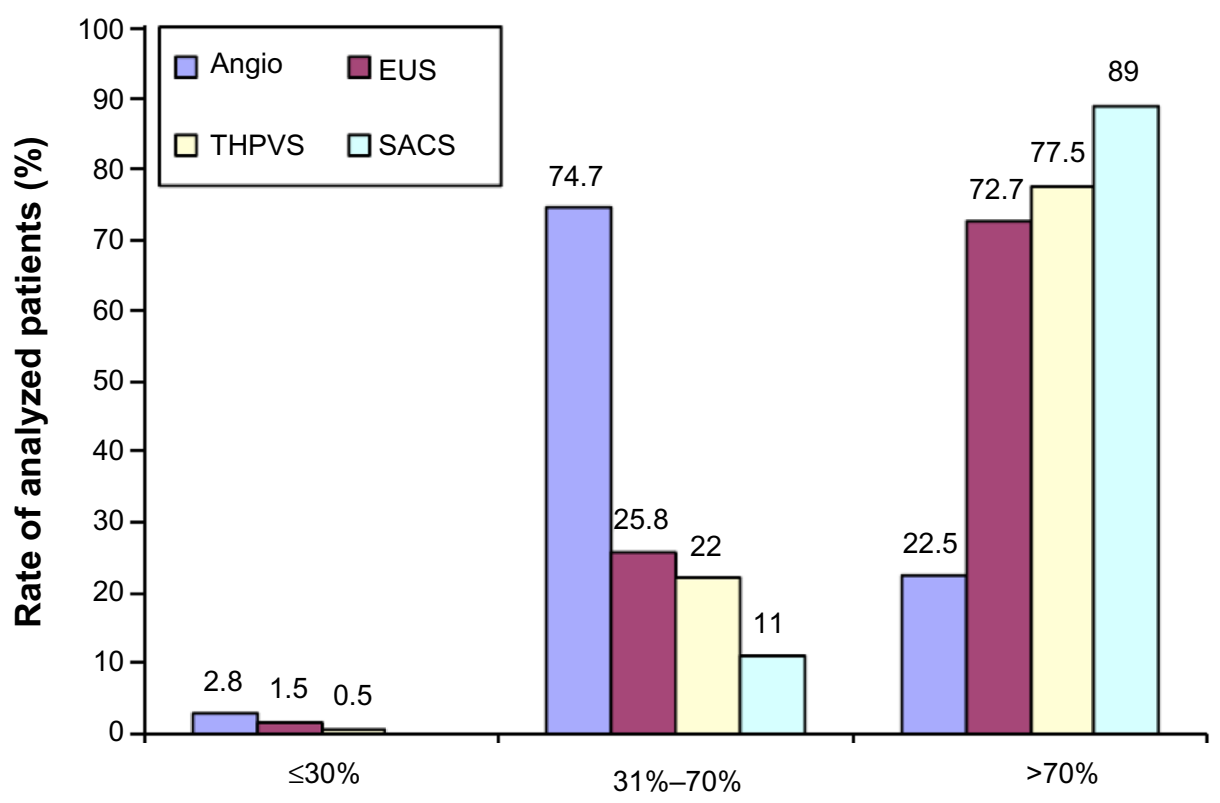

Distribution of sensitivity of preoperative invasive methods

Figure I The distribution of the sensitivity rate of preoperative noninvasive and invasive methods in the localization of insulinoma, in all published cases ( $\mathrm{n}=6,222$ ). Note: Reproduced with permission from Mehrabi A, Fischer L, Hafezi M, et al. A systematic review of localization, surgical treatment options, and outcome of insulinoma. Pancreas. 20I4;43(5):675-686. ${ }^{15}$

Abbreviations: Angio, angiography; CT, computed tomography; EUS, endoscopic ultrasonography; MRI, magnetic resonance imaging; SACS, selective arterial calcium stimulation; THPVS, transhepatic portal venous sampling; US, ultrasound.

of more than $70 \%$ and has intraoperative application, the special skills required to perform the procedure with minimal morbidity limits its broad application.

Among the invasive preoperative localization techniques, EUS and SACS have remained effective methods. EUS can detect lesions as small as $5 \mathrm{~mm}$ in the head of the pancreas with $92.6 \%$ success, but this value drops to $40 \%$ as one moves out towards the pancreatic tail. ${ }^{15}$ EUS was used in approximately $12 \%$ of insulinoma cases but achieved, on average, a $73.9 \%$ localization success rate. ${ }^{15}$ Lastly, the SACS test, since its introduction in 1989, has provided another technique for localizing insulinomas (especially those $<2 \mathrm{~cm}$ in size) to regions of the pancreas, both preoperatively and intraoperatively. ${ }^{17-19}$ This approach is based 
on the activity of calcium to stimulate the release of insulin from hyperfunctional $\beta$ cells in insulinomas, by selectively injecting calcium gluconate into major pancreatic arteries and subsequently measuring insulin levels from blood drawn from the hepatic veins via a second catheter (Figure 2). ${ }^{17-19}$ Measurements of insulin concentration in the hepatic vein are taken at 20,40, and/or 60 seconds after arterial infusion of calcium gluconate. ${ }^{17}$ A step up in insulin level by twofold indicates the anatomic region of the insulinoma in the pancreas. ${ }^{17}$ Like EUS, SACS is also operator-dependent and has a reported sensitivity of $84 \%-94 \% .^{15,17,18}$

\section{Operative localization/management of insulinoma}

Once an insulinoma is diagnosed biochemically and localized preoperatively, surgery is the next step. Surgical resection of insulinoma is the gold standard of care and provides the only means for curative treatment of the disease. ${ }^{9,13,15}$ Patients with the biochemical diagnosis of insulinoma achieve surgical cure

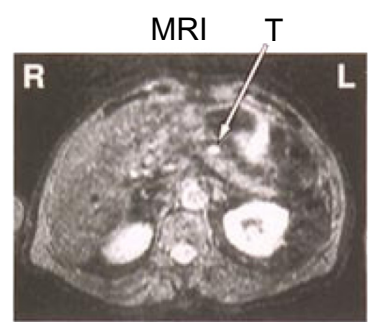

Arteriogram with calcium gluconate stimulation

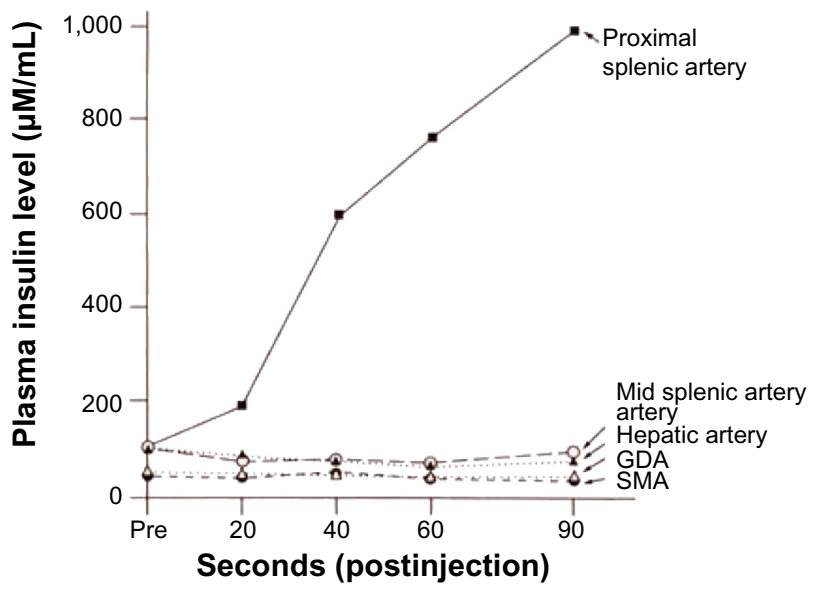

Figure 2 Left hepatic vein insulin concentrations after intra-arterial calcium injections.

Notes: Injections of the superior mesenteric artery, gastroduodenal artery, proper hepatic artery, and mid splenic artery do not show any suspicious areas. However, the increase in insulin concentration after injection into the proximal splenic artery localizes the lesion close to the pancreatic head area, corresponding to the MRI above (Photograph courtesy of Steven K Libutti and National Institutes of Health, Bethesda, MD, USA).

Abbreviations: GDA, gastroduodenal artery; MRI, magnetic resonance imaging; SMA, superior mesenteric artery; R, right; L, left; T, tumor. ranging from $77 \%$ to $100 \% .{ }^{9,20}$ The surgical approach can be open $(93.4 \%)$ or laparoscopic $(6.8 \%) .{ }^{15}$ Medical therapy is reserved for patients with malignant insulinoma with unresectable metastasis, comprising approximately $4.4 \%$ of the patient population. ${ }^{15}$ Cytoreductive surgery is also considered in a selected group of patients with metastatic insulinoma. ${ }^{13}$ Lastly, although few cases of robotic surgery for insulinoma have emerged in the last decade, the advantage of threedimensional view and enhanced dexterity of its articulated instruments have not translated to better outcomes than those for laparoscopic pancreatic surgery. ${ }^{21}$ The current surgical mortality rate for insulinoma ranges from $0 \%$ to $4 \%$, and the major morbidity rate is less than $20 \%{ }^{9,13}$

\section{Open approach}

Many consider the combination of IOUS and palpation by an experienced surgeon to be a superior technique of localization, achieving up to a $100 \%$ success (Figure 3). $4,9,15,18$ Localization with palpation for tumors less than $1 \mathrm{~cm}$ in diameter has a sensitivity of $69 \%$, which increases to $79 \%$ for tumors ranging from 1.2 to $3 \mathrm{~cm} .^{5}$ Intraoperative blood glucose monitoring has also been used to confirm the removal of all hyperfunctioning islet tissue, based on an increase of $30 \mathrm{mg} / \mathrm{dL}$ in blood sugar level in samples taken before and after tumor resection (Figure 3). ${ }^{15}$ Despite a reported sensitivity of $87 \%$, intraoperative blood glucose monitoring has been used very infrequently because hypoglycemia during the

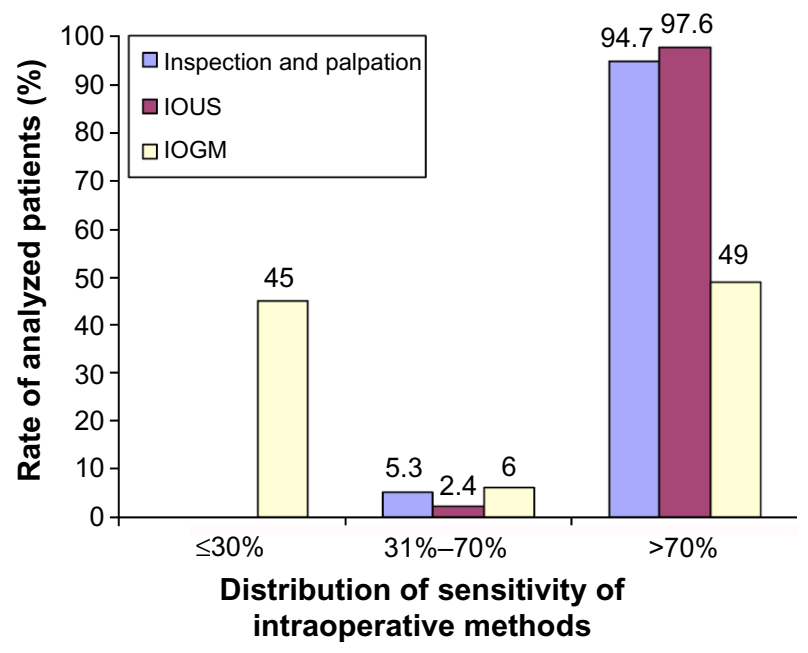

Figure 3 The distribution of sensitivity rates of intraoperative modalities in the localization of insulinoma, in all published cases $(n=6,222)$.

Note: Reproduced with permission from Mehrabi A, Fischer L, Hafezi M, et al. A systematic review of localization, surgical treatment options, and outcome of insulinoma. Pancreas. 2014;43(5):675-686. ${ }^{15}$

Abbreviations: IOUS, intraoperative ultrasound; IOGM, intraoperative glucose monitoring. 
operation is confounded by continuous infusion of glucose during general anesthesia. ${ }^{15}$

Different techniques for resection of insulinomas have been performed based on the location of the tumor. Enucleation (56\%), distal pancreatectomy (31.5\%), Whipple procedure (2.9\%), subtotal pancreatectomy $(2.5 \%)$, and, less than $1 \%$ of the time, total and central pancreatectomy have been applied. ${ }^{10}$ The benign nature of most insulinomas allows for enucleation as the procedure of choice when possible. ${ }^{13,22}$ Although guidelines for deciding which insulinoma lesions should be resected or enucleated are not well established, in general, most surgeons prefer local tumor resection when the lesion is deemed to be too large for safe excision, multifocal in the body or tail of the pancreas, or is too close to the pancreatic duct. ${ }^{22}$ In regards to tumors in the pancreatic head, enucleations can also be safely performed with the use of IOUS. However, pancreatic head lesions without a well-defined pseudocapsule, of size $>4 \mathrm{~cm}$, or that are multifocal or close to the main pancreatic duct should undergo pancreaticoduodenectomy. ${ }^{22}$ Lastly, for tumors not localized intraoperatively, blind distal pancreatectomies have been performed. This procedure, however, is now discouraged owing to the inaccuracy and lack of therapeutic success of the procedure, its morbidity, and advancements in intraoperative imaging. ${ }^{23}$

The operative steps of open insulinoma surgery involve the following key maneuvers (Figures 4-8): After laparotomy, the abdomen is explored for evidence of metastasis. The lesser sac is then entered through the gastrocolic ligament, exposing the anterior surface of the pancreas. Next, a Kocher maneuver is performed to mobilize the duodenum and the head of the pancreas. This allows bimanual palpation of the head of the pancreas. At this point, using IOUS to determine the location of the tumor(s) and their relationship to the pancreatic duct and vessels is critical. ${ }^{20}$ With the guidance of IOUS, insulinomas can be safely enucleated without entering the pancreatic ducts, thereby avoiding the possibility of

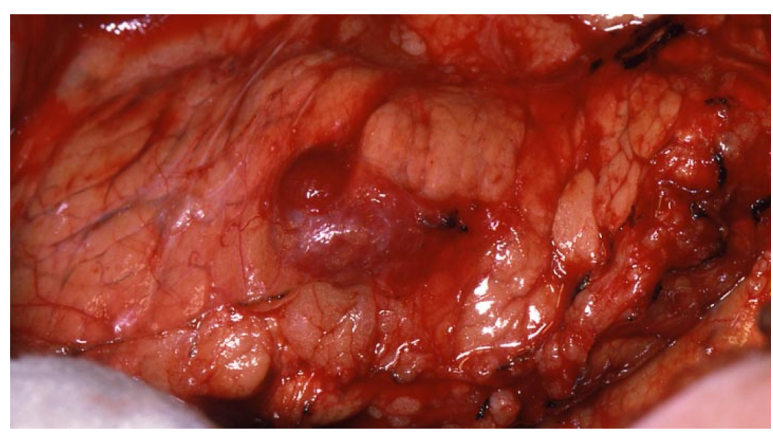

Figure 4 Intraoperative view of insulinoma.

Note: Photograph courtesy of Steven K Libutti.

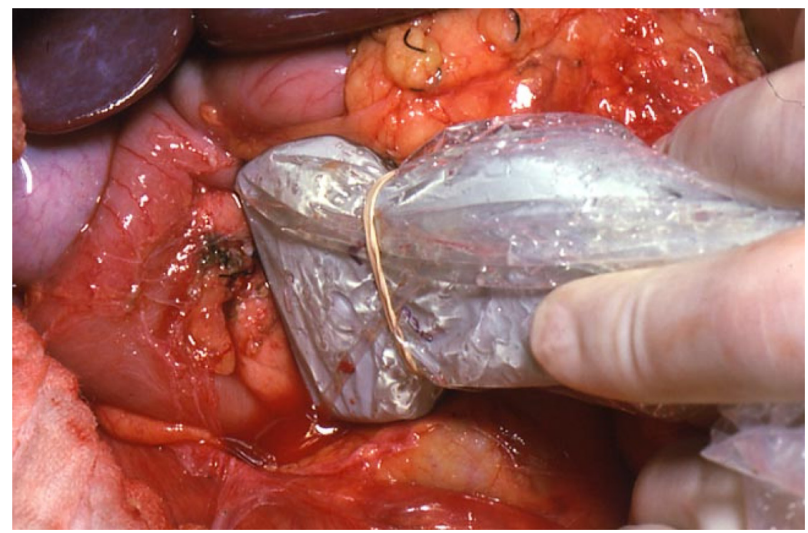

Figure 5 IOUS placed on insulinoma in Figure 4 to identify the location of the mass in relation to vascular structures and pancreatic duct.

Note: Photograph courtesy of Steven K Libutti.

Abbreviation: IOUS, intraoperative ultrasound.

postoperative pancreatic fistula. Tumors should be removed intact to prevent local recurrence. ${ }^{13}$

\section{Laparoscopic approach}

As the application of minimally invasive surgery advances in all fields of surgery, its utility in insulinoma management has also emerged. Successful laparoscopic surgery for insulinoma has been reported since $1995 .{ }^{24}$ Since then, several publications have demonstrated the procedure to be safe with the added benefit of shorter length of stay and faster recovery time. ${ }^{24,25}$ Insulinomas are suitable to laparoscopic excision, given their predominantly benign, intrapancreatic, and solitary nature. ${ }^{24}$ Laparoscopic approach is best suited when the tumor

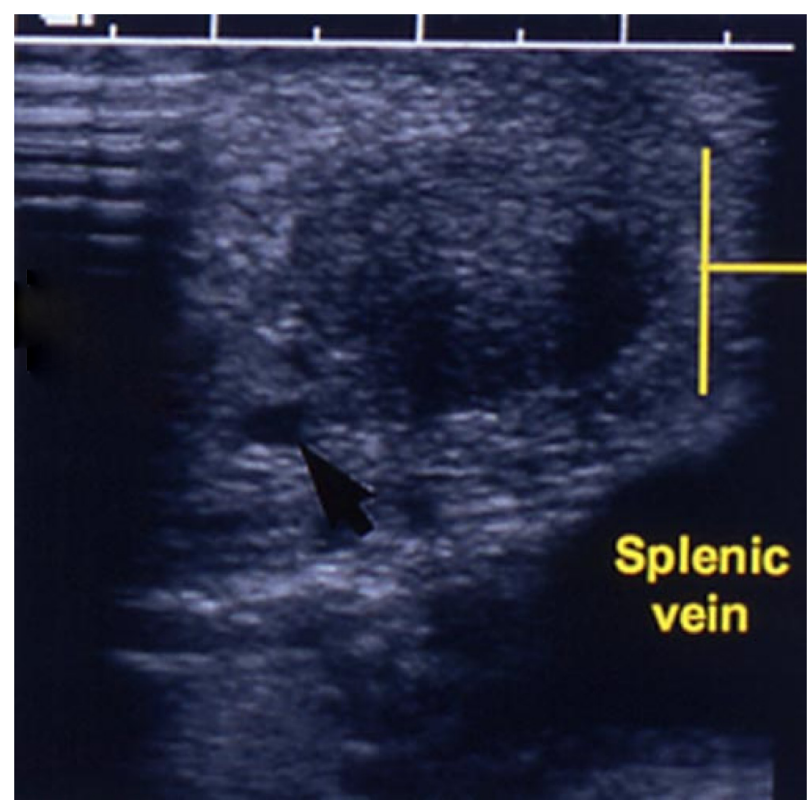

Figure 6 IOUS of Figures 4 and 5.

Notes: The black arrow is pointing to the pancreatic duct. The yellow lines are showing the insulinoma. Photograph courtesy of Steven K Libutti.

Abbreviation: IOUS, intraoperative ultrasound. 


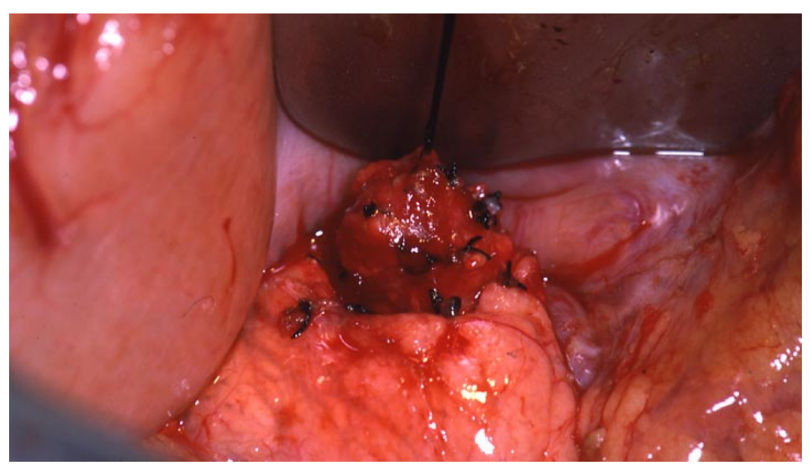

Figure 7 Enucleation of insulinoma seen in Figures 4, 5, and 6. Note: Photograph courtesy of Steven K Libutti.

is located on the surface of the pancreas and is further away from the main pancreatic duct. ${ }^{25}$ Insulinomas that are localized deep in the body or tail of the pancreas and that have close relationship with the pancreatic duct should undergo distal pancreatectomy. ${ }^{25}$ The application of laparoscopy in insulinoma resection is difficult when there are multiple tumors, tumors in the head or uncinate process, and lesions in the dorsal aspect of the pancreas, due to technical limitations of the approach. Therefore, tumor detection depends solely on laparoscopic ultrasonography, which achieves $86 \%$ to $90 \%$ localization..$^{24,26}$

\section{Missing insulinomas and surgical complications}

Despite advances in preoperative and intraoperative localization, approximately $13 \%$ of patients require reexploration. ${ }^{4}$ Morbidity rates increase from $21 \%-25 \%$ at the primary operation to $50 \%-58 \%$ after reoperation. ${ }^{4,27}$ At times, insulinomas are missed because there are multiple tumors, and these subjects should raise strong suspicion of MEN-I syndrome. ${ }^{27}$

Surgical complications include pancreatic fistula, pseudocyst, intra-abdominal abscess, pancreatitis, hemorrhage, and

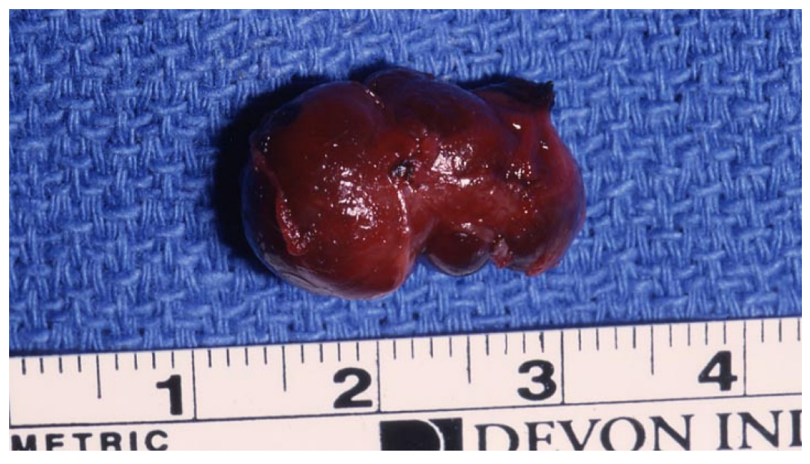

Figure 8 Final specimen of insulinoma as shown in Figure 4, 5, 6, and 7. Note: Photograph courtesy of Steven K Libutti. diabetes. ${ }^{9}$ Laparoscopic procedures carry similar rates of complication. ${ }^{25}$ Pancreatic fistulas are the most common complication for patients with insulinomas because of the soft texture of the gland. ${ }^{25}$ The majority of these complications are managed with conservative drainage and parenteral nutrition, with or without the addition of somatostatin analogs.

\section{Medical management of insulinoma}

Insulinoma patients who are awaiting surgery or who are not surgical candidates can be managed with medical therapy and dietary modification to avoid prolonged fasting. The initial drug of choice for patients with insulinoma is diazoxide, a nondiuretic benzothiadiazine derivative. Diazoxide was primarily introduced in the 1950 s for the treatment of hypertension; however, its side effects of hyperglycemia has made the drug applicable for the management of insulinoma. ${ }^{28}$ Diazoxide inhibits insulin release from $\beta$ cells via stimulation of $\alpha$-adrenergic receptors and also inhibits cyclic adenosine monophosphate phosphodiesterase, which enhances gylcogenolysis. ${ }^{13,29}$ A dose of $150-200 \mathrm{mg}$ in two or three divided doses per day can be titrated to a maximum dose of $400 \mathrm{mg}$ per day. ${ }^{13,29}$ Symptomatic control has been achieved in half the patients on diazoxide. ${ }^{6,13,28}$ The side effects of diazoxide are hirsutism, edema, gastrointestinal discomfort, weight gain, and nausea, yet, most patients tolerate it well. ${ }^{6,28}$

Somatostatin analogs octreotide and lanreotide have also provided another class of agents that are useful in the symptomatic management of insulinoma in patients with receptors for the drug. Natural somatostatin has a very short half-life of 2 minutes. ${ }^{30}$ Long-acting release octreotide and lanreotide both have high affinity towards SSTR2 and SSTR $5 .{ }^{30}$ These receptors are found in varying degrees on insulinomas. ${ }^{31}$ In about half the patients with insulinoma, octreotide and lanreotide binds these receptors and lower plasma insulin levels. ${ }^{30,31}$ The short-acting formulation octreotide can be dispensed in quantities of $50 \mu \mathrm{g}$ subcutaneously two or three times daily, increased up to $1,500 \mu \mathrm{g}$ daily..$^{13}$ Longacting release octreotide is administered intramuscularly with a dose of up to $30 \mathrm{mg}$ every 28 days, and $120 \mathrm{mg}$ of lanreotide is injected into the deep subcutaneous tissue every 28 days..$^{30,32}$ It is important to note that somatostatin analogs also act on other receptors involved in the regulation of growth hormone and glucagon secretion from alpha cells, thereby causing worsening hypoglycemia in some insulinoma patients..$^{30}$ The side effects of these somatostatin analogs are mainly gastrointestinal disturbances, such as nausea, emesis, diarrhea, constipation, abdominal pain, malabsorption, and cholelithiasis. $^{13}$ 
Recent studies have also focused on the antiproliferative and growth stabilization of somatostatin analogs on malignant NETs. ${ }^{30,32}$ Two studies, the placebo-controlled, double-blind, prospective randomized study on the effect of long-acting release octreotide in control of tumor growth in patients with metastatic neuroendocrine midgut tumors (PROMID) and the controlled study of lanreotide antiproliferative response in neuroendocrine tumors (CLARINET), have demonstrated promising prolonged progression-free survival among SSTRpositive NETs. ${ }^{32}$ The somatostatin analog mechanism of decreasing or arresting NETs growth has been attributed to the inhibition of cell proliferation of normal and tumor cells via induction of $\mathrm{G}_{1}$ cell cycle arrest and apoptosis. . $^{30,33}$ Although the success of these somatostatin analogs were mostly for small-bowel NETs and some pancreatic neuroendocrine tumors (PNETs), their antiproliferative-specific effects on insulinomas alone are yet to be defined. With regards to malignant insulinoma, establishing the presence of SSTR2 receptors in the primary tumor and in metastases may be valuable in avoiding severe hypoglycemia in patients without this receptor. ${ }^{33}$ Limited studies with variable outcomes have identified other SSTR subtypes involved in cell proliferation in malignant insulinomas, such as SSTR5 messenger (m)RNA expression, which could potentially be targeted for therapeutic options. ${ }^{33}$

Other agents that have been used for the medical treatment of insulinoma with various degrees of outcomes include phenytoin, verapamil, propranolol, glucocorticoids, and lastly glucagon. ${ }^{9}$

\section{Management of malignant insulinoma}

Malignant or metastatic insulinoma, spreading primarily to lymph node or liver, is a rare condition accounting for only $5 \%-12 \%$ of reported cases of insulinoma. ${ }^{14,34}$ These patients have a poor prognosis, with a median survival period of approximately 2 years. ${ }^{34}$ The initial surgery for tumor removal or diagnosis is the most important factor in the management of malignant insulinoma. ${ }^{34}$ Patients with a reasonable performance status, minimal extrahepatic disease, and resectable primary tumor are candidates for cytoreductive surgery. Unfortunately, curative cytoreductive surgery is effective in less than $10 \%$ of all patients with metastatic insulinoma. ${ }^{13}$

Medical interventions, namely diazoxide, hepatic embolization, chemotherapy (streptozocin, doxorubicin, and 5 -flurouracil), peptide-receptor radionuclide therapy, and radiofrequency ablation, have been mainly used for disease palliation. ${ }^{9,34}$
The chemotherapeutic agents everolimus and sunitinib have been recently approved for the management of advanced insulinoma, with promising progression-free survival and overall survival. ${ }^{35,36}$ Everolimus inhibits mTOR, a serine-threonine kinase that stimulates cell growth, proliferation, and angiogenesis, thereby inhibiting a pathway implicated with tumor proliferation of PNETs. ${ }^{36}$ Patients randomized to receive everolimus at a dose of 10 mg daily showed a median progression-free survival of 11 months compared with 4.6 months with placebo. ${ }^{36}$ Adverse effects were mostly stomatitis, rash, diarrhea, and fatigue, as well as anemia and hyperglycemia. ${ }^{36}$ Similarly, sunitinib, a multitargeted receptor tyrosine kinase inhibitor, has shown delayed tumor growth in PNETs by inhibiting VEGF and PDGF receptors (PDGFRs). ${ }^{35}$ Patients with PNETs who were randomized to therapy with a dose of $37.5 \mathrm{mg}$ of sunitinib daily had a median progression-free survival of 11.4 months compared with 5.5 months with placebo. ${ }^{35}$ The study was discontinued early due to more serious adverse events and death encountered in the placebo group. The most frequent side effects of sunitinib observed were diarrhea, nausea, vomiting, asthenia, and fatigue. ${ }^{35}$

\section{Conclusion}

Insulinoma is a very rare neuroendocrine tumor that has a unique presentation at the time of diagnosis. Patients with insulinoma develop symptoms such as confusion, dizziness, and palpitations that are relieved by consuming carbohydrate. Although it is predominantly a benign tumor, many biochemical tests and imaging modalities have been applied to properly diagnose and localize insulinomas. The 48-hour test can be used to accurately diagnose insulinoma in the majority of insulinoma patients, with very few having to complete the full 72-hour test. Preoperative CT scan is helpful in ruling out metastasis. Following the diagnosis of insulinoma, the definitive treatment of the tumor is surgery. IOUS, in conjunction with palpation, can correctly locate insulinoma. In the cases of missing insulinomas, SACS is a helpful tool to identify the anatomic region of the lesion in the pancreas. The medical management of insulinoma patients who are not surgical candidates or with malignant insulinomas has also seen many advances. In addition to the many available agents for symptomatic control of the disease, newly approved agents, such as sunitinib and everolimus, have had encouraging results in progression-free survival.

\section{Disclosure}

The authors report no conflicts of interest in this work. 


\section{References}

1. Service FJ. Hypoglycemic disorders. N Engl J Med. 1995;332(17): 1144-1152.

2. Whipple AO, Frantz VK. Adenoma of islet cells with hyperinsulinism: a review. Ann Surg. 1935;101(6):1299-1335.

3. Grant CS. Insulinoma. Baillieres Clin Gastroenterol. 1996;10(4): 645-671.

4. Richards ML, Gauger PG, Thompson NW, Kloos RG, Giordano TJ. Pitfalls in the surgical treatment of insulinoma. Surgery. 2002;132(6): 1040-1049; discussion 1049.

5. Boukhman MB, Karam JM, Shaver J, et al. Localization of insulinomas. Arch Surg. 1999;134(8):818-822; discussion 822-823.

6. Boukhman MP, Karam JH, Shaver J, Siperstein AE, Duh QY, Clark OH. Insulinoma - experience from 1950 to 1995. West J Med. 1998;169(2):98-104.

7. Callender GG, Rich TA, Perrier ND. Multiple endocrine neoplasia syndromes. Surg Clin NAm. 2008;88(4):863-895.

8. O'Riordain DS, O'Brien T, van Heerden JA, Service FJ, Grant CS. Surgical management of insulinoma associated with multiple endocrine neoplasia type I. World J Surg. 1994;18(4):488-493; discussion 493-494.

9. Shin JJ, Gorden P, Libutti SK. Insulinoma: pathophysiology, localization and management. Future Oncol. 2010;6(2):229-237.

10. Dizon AM, Kowalyk S, Hoogwerf BJ. Neuroglycopenic and other symptoms in patients with insulinomas. Am J Med. 1999;106(3):307-310.

11. Kennedy EP, Brody JR, Yeo CJ. Neoplasms of the endocrine pancreas. In: Mulholland MW, Lillemoe KD, Doherty GM, Maier RV, Simeone DM, Upchurch GR Jr, editors. Greenfield's Surgery Scientific Principles and Practice. Philadelphia, PA: Lippincott Williams \& Wilkins; 2011:857-871.

12. Vig S, Lewis M, Foster KJ, Stacey-Clear A. Lessons to be learned: a case study approach insulinoma presenting as a change in personality. $J$ R Soc Promot Health. 2001;121(1):56-61.

13. Mathur A, Gorden P, Libutti SK. Insulinoma. Surg Clin North Am. 2009;89(5):1105-1121.

14. Hirshberg B, Livi A, Bartlett DL, et al. Forty-eight-hour fast: the diagnostic test for insulinoma. J Clin Endocrinol Metab. 2000;85(9): 3222-3226.

15. Mehrabi A, Fischer L, Hafezi M, et al. A systematic review of localization, surgical treatment options, and outcome of insulinoma. Pancreas. 2014;43(5):675-686.

16. Hashimoto LA, Walsh RM. Preoperative localization of insulinomas is not necessary. J Am Coll Surg. 1999;189(4):368-373.

17. Guettier JM, Kam A, Chang R, et al. Localization of insulinomas to regions of the pancreas by intraarterial calcium stimulation: the NIH experience. J Clin Endocrinol Metab. 2009;94(4):1074-1080.

18. Brown CK, Bartlett DL, Doppman JL, et al. Intraarterial calcium stimulation and intraoperative ultrasonography in the localization and resection of insulinomas. Surgery. 1997;122(6):1189-1193; discussion 1193-1194.

19. Doppman JL, Chang R, Fraker DL, et al. Localization of insulinomas to regions of the pancreas by intra-arterial stimulation with calcium. Ann Intern Med. 1995;123(4):269-273.
20. Finlayson E, Clark OH. Surgical treatment of insulinomas. Surg Clin North Am. 2004;84(3):775-785.

21. Wayne M, Steele J, Iskandar M, Cooperman A. Robotic pancreatic surgery is no substitute for experience and clinical judgment: an initial experience and literature review. World J Surg Oncol. 2013;11:160.

22. Park BJ, Alexander HR, Libutti SK, et al. Operative management of islet-cell tumors arising in the head of the pancreas. Surgery. 1998;124(6):1056-1061; discussion 1061-1062.

23. Hirshberg B, Libutti SK, Alexander HR, et al. Blind distal pancreatectomy for occult insulinoma, an inadvisable procedure. J Am Coll Surg. 2002;194(6):761-764.

24. Berends FJ, Cuesta MA, Kazemier G, et al. Laparoscopic detection and resection of insulinomas. Surgery. 2000;128(3):386-391.

25. Zhao YP, Zhan HX, Zhang TP, et al. Surgical management of patients with insulinomas: Result of 292 cases in a single institution. J Surg Oncol. 2011;103(2):169-174.

26. Grover AC, Skarulis M, Alexander HR, et al. A prospective evaluation of laparoscopic exploration with intraoperative ultrasound as a technique for localizing sporadic insulinomas. Surgery. 2005;138(6):1003-1008; discussion 1008.

27. Simon D, Starke A, Goretzki PE, Roeher HD. Reoperative surgery for organic hyperinsulinism: indications and operative strategy. World $J$ Surg. 1998;22(7):666-671; discussion 671-672.

28. Goode PN, Farndon JR, Anderson J, Johnston IDA, Morte JA. Diazoxide in the management of patients with insulinoma. World J Surg. 1986; 10(4):586-592.

29. Fajans SS, Floyd JC, Thiffault CA, Knopf RF, Harrison TS, Conn JW. Further studies on diazoxide suppression of insulin release from abnormal and normal islet tissue in man. Ann N Y Acad Sci. 1968;150(2): 261-280.

30. Arnold R, Wied M, Behr TH. Somatostatin analogues in the treatment of endocrine tumors of the gastrointestinal tract. Expert Opin Pharmacother. 2002;3(6):643-656.

31. Vezzosi D, Bennet A, Rochaix P, et al. Octreotide in insulinoma patients: efficacy on hypoglycemia, relationships with Octreoscan scintigraphy and immunostaining with anti-sst2A and anti-sst5 antibodies. Eur $J$ Endocrinol. 2005;152(5):757-767.

32. Caplin ME, Pavel M, Ćwikła JB, et al; CLARINET Investigators. Lanreotide in metastatic enteropancreatic neuroendocrine tumors. N Engl J Med. 2014;371(3):224-233.

33. Ferrer-García JC, Iranzo González-Cruz V, Navas-DeSolís S, et al. Management of malignant insulinoma. Clin Transl Oncol. 2013;15(9): 725-731.

34. Hirshberg B, Cochran C, Skarulis MC, et al. Malignant insulinoma: spectrum of unusual clinical features. Cancer. 2005;104(2):264-272.

35. Raymond E, Dahan L. Raoul JL. Sunitinib malate for the treatment of pancreatic neuroendocrine tumors. N Engl J Med. 2011;364(6):501-513.

36. Yao JC, Shah MH, Ito T. Everolimus for advanced pancreatic neuroendocrine tumors. N Engl J Med. 2011;364(6):514-523.

Research and Reports in Endocrine Disorders

\section{Publish your work in this journal}

Research and Reports in Endocrine Disorders is an international, peerreviewed, open access journal publishing original research, reports, reviews and commentaries on all areas of endocrinology, endocrine disorders and therapeutic interventions. The manuscript management system is completely online and includes a very quick and fair

Submit your manuscript here: http://www.dovepress.com/research-and-reports-in-endocrine-disorders-journal

peer-review system. Visit http://www.dovepress.com/testimonials.php to read real quotes from published authors. 